\title{
The Heavy-Chemical Industrialization Policy Reevaluation in Korea from the Perspective of the "General Theory of Economic Development"
}

\author{
Dr. Jwa Sung-Hee \\ President Park Chung-hee Memorial Foundation \\ Korea \\ Prof. Dr. Lee Sung-Kyu \\ Department of International Trade \\ Andong National University, Korea
}

\begin{abstract}
The purpose of this study is to call attention to the distorted view of mainstream economic circles towards Korea's past heavy-chemical industrialization policy, which was the leading national industrial policy of the country, based on a new economic development theory, and then to demonstrate that it was a successful market-friendly industrial policy. On the basis of the "General Theory of Economic Development", this study particularly intends to re-identify the economic policy paradigm of the Park Chung-hee era as a "heavy-chemical industrialization strategy", rather than as an "export-led growth strategy" as considered by mainstream economic circles. To this end, this study suggests the necessity of a new interpretation of Korea's industrialization process as it examines the actual implementation process of the policy. This study also explains "the holy trinity of economic development", that is, the market, corporation, and government, in line with the General Theory of Economic Development. To this end, this study examines the major criticisms of the heavy-chemical industrialization policy, and reevaluates the policy from the viewpoint of the General Theory of Economic Development. Based on the results of the above analysis, this study drew the following three conclusions. First, the success of the heavy-chemical industrialization strategy ultimately contributed to the accomplishment of the industrial revolution in Korea by elevating and developing the Korean economy from a 'carriage manufacturing economy' into an 'automobile manufacturing economy'. Second, Korea's economic development was led by the growth of corporations, and thus, by the paradigm of the corporate contribution to the national prosperity and development. Finally, the industrial policy of government-controlled economic discrimination has contributed to the successful industrialization of Korea.
\end{abstract}

Keywords:Economic discrimination by market, Principle of award and penalty, Heavy-chemical industrial policy, Theholy trinity of economic development, Economic discrimination by the government, Developmental economics model, The General Theory of Economic Development.

\section{JEL Classifications: O14, O25, O38, 053.}

\section{Introduction}

If asked "What is the most important economic policy that has led Korea's economic development?", most of the Korean economists would attribute the answer to the 'export-led growth strategy'. However, the most popular policy among developing countries in the 1960s and 1970s was the "infant industry protection and promotion strategy" to support and nurture industries that were still in their infancy. This sort of policy has some merit in part. The reason is that it is obvious that economic development through industrialization can only be achieved by cultivating and developing a new manufacturing industry in an agricultural society. Also, given the domestic situations of the then underdeveloped countries, where the manufacturing industry was still in its infancy and was not able to compete with those of industrialized nations, it seems apparent that such developing industries should be provided with support until they gained some competitiveness by protecting them from import competition. This viewpoint can be considered logically flawless. This sort of strategy is called "import substitution industrialization strategy".

The problem, however, was that there were few successful cases of the strategy that were known to the world at that time. Moreover, many limitations were being exposed in the process of the strategy implementation. In particular, the process produced various adverse effects, including the difficulty in selecting the companies to be supported. This was namely with respect to the problem of selecting the winners in advance. Another result was the corruption caused by the cozy relations between politics and business due to the protection and support of the government. 
However, the policy was highly popular in underdeveloped or developing countries as there was no other alternative to such a strategy.In the case of Korea, however, the Park Chung-hee government that rose to power after the May 16 military coup d'état in 1961 transformed the "import substitution industrialization strategy" into an "export-led growth strategy" through many political and economic changes. For example, in order to raise new industries, factories had to be built, which required foreign capital. Under this reasonably realistic assessment, the Park Chung-hee government had no choice but to catalyze exporting for earning foreign currency. This was a judgment based on an objective and practical evaluation of reality that was inevitable at that time. It is also well known that the foundation for Korea's economic growth was created through the government's efforts to nurture the export industry as well as the achievements that followed.

Based on the success of the export-led growth strategy, the Park Chung-hee government concentrated all its policy competencies on fostering the heavy-chemical industry, which was the final goal of the industrialization of the then Korea, from 1973. Here, it is important to note that, despite the objective to nurture the heavy-chemical industry, it eventually returned to the strategy of nurturing capital-intensive and higher value-added industries. Practically, this shift meant an import substitution industrialization strategy or an infant industry fostering strategy that was beyond the stage of promoting labor-intensive export industries. However, at the time, as previously mentioned, the accumulation of failure cases of the infant industry promotion policy led to a strong opposition to the government-led industrial policy mainly from the world economic circles. From the beginning, therefore, the policy to foster the heavy-chemical industry was faced with many objections from domestic and foreign academia. Meanwhile, some have insisted that the October Yusin(Restoration), the most controversial event of the Park Chung-hee era that was implemented in the same period, was inevitable for the success of the heavy-chemical industrialization. This argument, regardless of whether it is factually sound, caused the misunderstanding that the heavy-chemical industry promotion policy began with a dishonest political motive ${ }^{1}$. Furthermore, following the sudden death of President Park Chung-hee, who was the creator of the heavy-chemical industry promotion strategy, on the threshold of the completion of the projects carried out under the strategy, the strategy lost the opportunities to be fairly evaluated. Furthermore, the succeeding Chun Doo-hwan government (The Fifth Republic of Korea), along with the World Bank, declared the strategy as the "failure of the heavy-chemical industrialization policy"2. As a result, Korea's heavy-chemical industrialization policy has become a subject of avoidance rather than a subject of research. Consequently, there have been few studies that discuss the merits and demerits of the policy, and the principle of its success has become in the mainstream economics of Korea.

For this reason, the interpretation that the core of Korea's economic development strategy is the so-called "export-led growth policy" has become dominant in academia. Furthermore, the mainstream economic circles still maintain such a viewpoint. As this interpretation is consistent with the belief in free trade and the advocacy of anti-industrial policy in the market-oriented mainstream economics, it has also been embraced by the mainstream economic circles without causing significant disagreement. That is, Korea's heavy-chemical industry promotion policy was not only against the beliefs of the mainstream economic circles but also stigmatized as a failed policy, which made it increasingly neglected by the academia. As a result, it has become an accepted reality and a norm in that nobody hesitates to insist that the core of Korea's economic development strategy is an export-led growth strategy. In addition, it has become common knowledge that the export-led growth strategy was the right choice for Korea at the time. This also meant that it was a wrong decision to implement the heavy-chemical industrialization strategy due to its severe side effects, in spite of some of its achievements. Furthermore, the economic circles have adopted an equivocal attitude towards Korea's past heavy-chemical industrialization strategy; they cannot expressly deny the significance of the strategy due to its accomplishments, but are reluctant to willingly insist that the policy was necessary at the time ${ }^{3}$.

\footnotetext{
${ }^{1}$ This notion was asserted by Oh Won-cheol (2006), who served as a senior secretary in charge of the heavy-chemical industry at the time. Kim Hyeong-a (2005) had also made the same argument. However, the then Chief Secretary Kim Jeong-ryeom and the then secretary of the heavy-chemical industry Kim Gwang-mo (2015), insisted that although the October Yusin (declared on October 17, 1972, with the Yusin Constitution having passed on December 27 in the same year) had contributed to the heavy-chemical industrialization of Korea, it is not true that the October Yusin had been carried out for this purpose in light of the related facts. Furthermore, President Park Chung-hee did not mention the heavy-chemical industrialization in the Declaration of Yusin.

${ }^{2}$ Some of the examples include: The announcement of the Subcommittee on Commerce and Industry of the Special Committee forNational Security Measures on August 19, 1980; and the Korea Development Institute's Economic and Social Policy Council documents for the establishment the 5th Five-Year Economic Development Plan ("The Measures to Reestablish the Basic Tasks of the Industrial Policy and Support Measures", 1982). The World Bank was critical of the policy from the time it was launched. The institution encouraged the reconsideration of the policy in 1974, and maintained the same stance after the establishment of the Fifth Republic of Korea. For a detailed overview of these data, see Park Yeong-gu (2008, Chapter 12).

${ }^{3}$ Regarding this, refer to the Korea Development Institute (1995), the Compilation Committee for the 60-Year History of Korean Economy (2010, Volume 1), and Sakong\&Koh (2010).
} 
Based on the new "General Theory of Economic Development", this study attempts to assert that the economic policy paradigm of the Park Chung-hee government era should not be described as an export-led growth strategy, as observed by the mainstream economics academy, but as a heavy-chemical industrialization policy. That is, it seeks to logically demonstrate that the success of the Park Chung-hee government can be, in essence, attributed to the selection and fulfillment of the heavy-chemical industrialization strategy.

This study develops itself in the following order. Chapter 1 emphasizes the necessity of a new interpretation of the process of the industrialization of Korea. In Chapter 2, the actual implementation process of the Korean heavychemical industrialization policy is examined from a new approach. Chapter 3 explains the theory of "the holy trinity of economic development" involving the market, corporation, and government, in line with the General Theory of Economic Development. Chapter 4 examines the major criticisms of the heavy-chemical industrialization policy and then evaluates Korea's policy from the viewpoint of the General Theory of Economic Development. Finally, Chapter 5 summarizes the key assertions regarding the policy and the respective lessons learned.

\section{A New Interpretation of the Korean Heavy-Chemical Industrialization Policy}

\subsection{The Significance of the Success of the Korean Heavy-Chemical Industrialization Policy}

The "equation of success" can generally be obtained from successful cases, rather than from failure cases. While learning from the failures of others can be constructive, avoiding failure altogether or doing the opposite of what caused the failure does not necessarily lead one to success. Meanwhile, while modeling after a successful case does not always guarantee success, it raises the possibility of attaining success ${ }^{4}$. Here, we can understand how significant Korea's experience of the success of the heavy-chemical industry promotion policy is. In the shortest period in the history of the world and under the most unfavorable economic conditions, the country transformed itself from a typical agricultural society from approximately 60 years ago into an industrial society by successfully executing an industrial revolution for about 20 to 30 years. Korea is now on the threshold of a knowledge-based economy society. Figuratively, Korea started from a "carriage manufacturing economy", established an "automobile manufacturing economy", and is now moving forward into an "airplane manufacturing economy". Of course, at this last stage of development, the Korean economy faces the challenges of low growth and polarization. This study argues that the reason is that the government has ignored the success principle of industrial policies while implementing economic development policies.

The industrialization of Korea provides the only successful model for industrial policies in the world in the latter half of the 20th century. It is a valuable experience from which we learn the principle of rejuvenating the mainstream economics taught in universities that has been trapped in abstraction, into a practical discipline for economic development. If we can theorize and generalize the principle of success from this experience, it will serve as an important starting point to open a new path to "developmental economics" that can solve the problems of low growth and polarization that the seven billion people on Earth currently face.

To date, Korea's heavy-chemical industrialization policy has been labeled a "failed policy" under the lack of understanding of the domestic and foreign mainstream economic circles that were skeptical about this policy and the bureaucrats of the Fifth Republic of Korea. Meanwhile, President Park Chung-hee, who was the designer and the powerful proponent of this policy, suddenly passed away before celebrating its fulfillment. For this reason, Korea has continued to develop for about 40 years without having the opportunity to fairly evaluate and review this policy. However, it is necessary to understand that the "three-low boom" during the 1980s and the dramatic breakthrough in the Korean economy since then, which included the country's triumph in overcoming the foreign exchange crisis in the late 1990s, were yielded by the export competitiveness of the heavy-chemical industry companies, which was the fruit of the industrial policy implemented by the Park Chung-hee government. Nonetheless, the Korean mainstream economic circles do not fully comprehend the principle of the success of this policy, nor do they attempt to understand it to the present day.

\subsection{A New Interpretation of the Korean Heavy-Chemical Industrialization Policy}

How, then, can we understand the success of Korea's heavy-chemical industrialization policy? Above all, we first answer the question about "how to overcome the problems in the actual implementation process of the policy", discarding the assertion based on the "theory of comparative advantage" that it did not fit the reality of Korea at the time. First, we consider the question of "which industries should be selected as promising industries".

\footnotetext{
${ }^{4}$ Acemoglu and Robinson (2012) recently stated in their book Why Nations Fail that the cause of the failure of "inclusive growth" was not an exploitative system but rather a democratic political system. However, as the possibility of the failure of democracy is overlooked, they fail to find a successful equation of inclusive growth.
} 
Regarding this matter, Korea had the fortune of enjoying free riding following the precedent of Japan's economic development. Korea closely watched the industrialization process of its neighbor Japan, the first Asian country to achieve success in the shortest period at the time by benchmarking the West. President Park Chung-hee, the pioneer of the heavy-chemical industrialization policy, Chief Secretary Kim Jeong-ryeom who assisted President Park, and Senior Secretary Oh Won-cheol who was in charge of the policy implementation, were all driving forces who were "made in Japan". That is, they were born during the Japanese Occupation of Korea and received a Japanese education. These figures were well acquainted with the implementation process of Japan's industrial policy since the Meiji Restoration until the post-war reconstruction period. Therefore, they were in a strong position to understand "which industry should be selected and fostered to achieve an industrial revolution". Of course, the fact that Korea was the only country that quickly enjoyed free riding to the successful model of Japan, though considered a public good, suggests that Korea had its own level of expertise. Therefore, although the precedent of Japan might not be a perfect theory, Korean was able to greatly reduce the risk of failure in the selection of promising industries.

Second, the issue of "which companies need to be supported first" is more difficult to address than that of selecting the industries to foster. What is unique about Korea's past export promotion policy and related corporate policies is that the companies that eagerly lived up to the national policies and performed well had always been favored. That is, the Korean government implemented corporate support policies based on their export performance under the principle of award and penalty, thereby strongly motivating companies to gain competitiveness in exporting and maximizing incentives for growth. In this way, the performance of companies in the market was considered a top priority in all support policies. This principle, though imperfect, provided a solution to the "problem of choosing the winners in advance". The reason why post-selection according to market performance can be a useful solution to the winner selection problem is that, as F.A. Hayek expressed, the "competition as a discovery procedure" determines the winner and the loser only after the competition is finished ${ }^{5}$. Post-selection on the basis of market performance can be described as the reproduction of the functions of the market, whereas pre-selection logically involves the dismissal of the functions of the market. The problem of the pre-selection of winners, in general, served as the grounds for a skeptical viewpoint that the government's economic intervention will inevitably lead to failure. It is quite remarkable that there was no debate on the possibility that the government can perform the function of the post-selection of winners as does the market in mainstream economic circles. This may be attributed to the lack of awareness about the market's function of discriminatory selection, which will be discussed in the next chapter.

The Korean government always allowed the "enterprises that had already been recognized for their achievements" to enter the heavy-chemical industry sector in the stage of promoting export. At the time, in the operation of the National Investment Fund, which was created to foster the heavy-chemical industry, the government required the participating companies to self-procure $25 \%$ of the investment fund. The remaining $75 \%$ was supported by the National Investment Fund ${ }^{6}$. Finally, manufacturing plant construction was planned at an "international-level" scale so that the industry would gain international competitiveness through economies of scale. As a result, the participating companies were forced to self-procure $25 \%$ of the required capital, which was considerably larger than the average capital scale of Korean companies at the time. As a result, the government selected only the "most capable companies that could accumulate that level of capital through excellent performance". The selection occurred in the stage of promoting export to give these companies permission to enter the heavy-chemical industry in a discriminatory way. In this way, the Korean economy was able to avoid the risk of failure that the pre-selection policy would have involved due to imperfect information about the future.

However, there still remains another difficult question: Does a company's past and present good performance guarantee their future good performance? The answer is, of course, is "not always". To some degree, however, the company can be deemed more likely to continue to perform well in the future. Although the question is not simple to answer, we can at least understand that post-selection is the "best alternative" in the light of the selection process in the market. Nevertheless, the best information to predict the future is that of the past and present as no one other than God knows the future. As a result, economic subjects in the market have no choice but to select companies based on information or results already known and revealed.

\footnotetext{
${ }^{5}$ Market competition is a scientific procedure for the discovery of winners. See Hayek (1984) for details.

${ }^{6}$ In order to increase the capital adequacy of the participating companies, the government's Heavy-Chemical Industrialization Planning Group mandated the companies to maintain a 30:70 ratio of the capital to liabilities. The internal administrative guidelines on the procurement of the required capital were also established and followed to mandate the participating companies to procure $15 \%$ of the capital by themselves while the remaining $75 \%$ was supported by the National Investment Fund. (This is based on the testimony of Oh Won-cheol, the second Senior Secretary of Economic Policy, who also headed the Heavy-Chemical Industry Planning Group at the time).
} 
Therefore, it is difficult to determine whether the market should be allowed to choose the winners based on the information about their market performance obtained after their competition, or whether the government should select companies based on the same information after their competition is the logically right decision. The difficulty in decision-making would be more so challenging in underdeveloped countries where information is less complete in the market. In the end, Korea overcame the difficult challenges in the course of the implementation of the heavy-chemical industrialization policy by selecting the winners after their market competition, which is deemed the "best alternative".

In addition, the social overhead capital supply policy that the Korean government carried out at the same time greatly contributed to the success of the heavy-chemical industrialization policy. First, the government formed the heavychemical industrial complexes considering the locational conditions of specific industries and invited the appropriate enterprises to locate their facilities within the compound. To effectively supply skilled manpower to these highprecision industries, various manpower supply plans such as education programs were prepared in advance and successfully implemented. In addition, for post-management, the government applied strict rules and functioned as a stern overseer to supervise and encourage the participating companies based on the information about their performance in the market.

More interestingly, the economic and social policies that were implemented by the Korean government during the development period, such as the export promotion policy, SaemaulUndong (New Community Movement), makingforest-green project, as well as the heavy-chemical industrialization policy, were all based on the principle of discriminatory selection and support. In fact, all these public policies are intended to foster the development of the public or private sector by utilizing the administrative power or fiscal capacity of the government and are all included in the category of industrial policy in a broad sense ${ }^{7}$. In the end, these public policies contributed to the modernization and industrial revolution of Korea by achieving success through the discriminatory selection and support policies.

How, then, can we theoretically explain the success of these policies? What significance does the selection depending on market performance and discriminatory support, a strategy chosen by the Korean government, have? This strategy is consistent with the 'market principle', which never changes. The reason is that the market always selects only the individuals and companies that achieve good results and discriminatively supports them. The market is an effective device that induces economic subjects to pursue growth and development, granting outstanding performers the award of survival and growth, and imposing the penalty of exclusion on those without achievement. As a result, the market is a social system that helps the society to achieve economic growth and development by repeatedly implementing "industrial policies" through discrimination every day. The combination of the market principle and industrial policies yields the following important implications: The industrial policy of Korea enabled the country to execute an industrial revolution and achieve remarkable economic development in the shortest period of time in the history of humankind as the government reproduced and performed the function of the market, which entails discriminatory selection and support, and practiced the principle of a market-led industrial policy. This study demonstrates this concept in the following chapter on the General Theory of Economic Development.In sum, the Korean heavy-chemical industrialization policy was based on the joint implementation by the market and the government of discriminatory selection depending on the companies' performance. This economic discrimination strategy invited only the companies with accomplishments to the heavy-chemical industrialization project and selectively supported them. This selection strategy made it possible for Korea to greatly advance from a "carriage manufacturing economy" into an "automobile manufacturing economy" in about 20 years. Here, the key factor to the success was the government's role, which was to properly reproduce the market's function of implementing an industrial policy and to strengthen the impact of competition in the market economy. If the government had intervened against the market's function of discrimination, the economic development may have been impeded by slowing down the market's function of motivation. Then, the following question can be posed: Why should the government perform such a function when the market can be left to function on its own? The reason why the government should perform the function of economic discrimination can be found based on a new analysis framework called the "General Theory of Economic Development".

\section{The General Theory of Economic Development}

What is the General Theory of Economic Development? This chapter explains in detail the General Theory of Economic Development by the holy trinity of economic development, which comprises the market, corporation, and government.

\footnotetext{
${ }^{7}$ Public policies, such as the government's educational policies, health insurance, social insurance, and social safety net policies, andeven social overhead capital supply and macroeconomic policies, are all aimed at correcting the market failure due to imperfect information. Thus, in theory, they can be classified as industrial policies by their nature. SeeRodrik (2008) for details.
} 


\subsection{The Market's Economic Discrimination Function and the General Principle of Economic Development}

This study intends to present the General Theory of Economic Development based on the new interpretation of Korea's success experience and the function of the market discussed in Chapter $2^{8}$. The General Theory of Economic Development is grounded on a new definition of market function. First, the theory gives the following new definition to the market.

\section{$<$ Definition 1>The market is a device of motivation for economic development through economic discrimination and a necessary condition for economic development.}

Economic discrimination refers to merely "considering economically different elements as different from each other" and does not imply any political or social discrimination. In contrast, "economic egalitarianism" is to "consider economically different elements as the same", which impedes motivation by denying the difference in performance. Therefore, economic egalitarianism is the opposite of economic discrimination. Thus, while economic discrimination is a necessary condition for economic development, economic egalitarianism is a sufficient condition for economic stagnation. This principle is not an outcome of abstraction by deductive reasoning but an inductive conclusion derived from observation of the real market. Why is this so? In the real world, the market is a social system and device that helps only those who help themselves in accordance with the principle of award and penalty. How is the market observed in the real world? To illustrate, a consumer chooses only the companies that produce the products that satisfy them most, and as a result, only the best companies survive in the market. Banks prefer to engage with only top-ranking companies and individuals. Investors in the stock market always select and support only excellent companies. Accordingly, corporations also always select and employ highly talented people while these talented individuals prefer only outstanding companies. These examples illustrate the market's function of economic discrimination in the real world. Therefore, the market continuously motivates economic subjects by performing the function of discrimination, thereby leading them to voluntarily pursue economic development and prosperity. This general principle suggests that an economy in which the economic discrimination function works well in the market will grow and develop more rapidly.

The market's discrimination function can be interpreted as an economic expression of the Western idea that is connoted in the proverb "heaven helps those who help themselves"9 and the concept of the "award and penalty" advanced by the School of Law during the Qin Dynasty ${ }^{10}$. Only the society in which the economic subjects who work diligently and excel over others are better treated can achieve greater wealth and prosperity. This idea is not only indicative of the common sense of the world that humankind has learned in the course of many years of evolution, but it is also based on the law of evolution ${ }^{11}$. In such a society where the principle of economic discrimination is universally respected and practiced, economic subjects display in their spirit a high level of self-management, self-reliance, and creativity, which is why this type of society and state is more likely to transform itself from a "carriage manufacturing economy" into an "airplane or spaceship manufacturing economy".

\subsection{Market Failure and Economic Development Failure due to Free Riding}

In reality, the process of economic development is more complex than it seems. The process of the development of individuals, companies, countries, and even civilizations involves the transition from a carriage manufacturing economy into a much more complex economy that includes the manufacturing of aircraft or spacecraft by imitating or following the "success know-how". In a few words, the evolution of humanity can be defined as "a propagation process of the implicit knowledge or success know-how". However, the essential characteristic of the implicit knowledge or success know-how market is that one can easily get a "free ride" on the knowledge and success know-how of others ${ }^{12}$.

\footnotetext{
${ }^{8}$ The General Theory of Economic Development is introduced in detail in Jwa (2017). The topic of the book is on the theory of economic development that newly interprets the world economic development based on the economic growth and development experience of the three Northeast Asian countries, including Korea, Japan, and China. The text focuses on the industrial revolution in the West and in Korea. On the other hand, Jwa (2017a) presents a new interpretation of the history of Korean economic development by applying this theory. The market-friendly industrial policy examined in this study is also based on the book.

${ }^{9}$ The proverb appears to have originated from the Parable of the Three Servants (Talents) in Matthew 25 of the Holy Bible.

${ }^{10}$ This idea was advanced by Guanzi, Han Feizi, and other scholars in the School of Law during the Warring States period of China. They placed greater importance on the rule of the law than on the rule of virtue, and believed that strictly rewarding those who performed good deeds and punishing those who committed wrongful deeds was the basic principle to rule the state.

${ }^{11}$ The theory of evolution proposes that a given environment selects the fittest. The fittest refers to an entity that exhibits the characteristics or performance that the environment prefers. Therefore, the environment is analogous to God who helps those who help themselves and practices the law of award and penalty.

${ }^{12}$ The term "free riding" used here is another expression of an "external economy", and from the aspect of evolution, it is another expression of reproduction. The reason why the term "free riding" is preferred in this study is that it is suitable to express the viewpoint toward the economic development of the General Theory, which proposes that it is the "intentional behaviors" of humans for their self-
} 
Why is this so?

All transactions in the market presuppose agreement on all the transaction terms between those involved in the transaction, such as the quantity and quality of the goods to be traded, the conditions for the delivery of the goods, the various contracts required for the transaction, and the various sanctioning devices to guarantee the fulfillment of the contracts. However, this agreement process requires the expenditure of time and effort, and sometimes monetary costs, to obtain and confirm information. The reason is that the process is imperfect with respect to all these conditions, and the costs arising from the process are called "transaction costs". The more complex the nature of the traded goods and the more difficult it is for the related parties to trust each other, as there is a distance between them as in international transactions, the higher the transaction costs are. If the transaction costs are too high and the parties cannot reach an agreement, the market transaction cannot take place and the goods become free goods that are subject to free riding and eventually disappear from the market. The more complex the characteristics of the goods are and the more imperfect the related information is, the higher the transaction costs become and the more pervasive free riding becomes.

It is difficult to establish the price of the implicit knowledge goods of success know-how in the market as they create high transaction costs due to the complexity of their nature. Therefore, in many cases, market transactions hardly occur for the goods. The knowledge already created is subject to free riding similar to free goods, and the knowledge that has not yet been created cannot come into existence. In this case, the market's selection and the discrimination functions are not completely performed. This leads to market failure due to free riding. If free riding on others' knowledge becomes pervasive, outstanding workers and companies cannot be properly rewarded for their excellent performance. This, in turn, leads to the loss of incentives that encourage individuals and enterprises to work harder for their success in the market, that is, economic development. Therefore, economic development failure will occur if the market fails to perform its function of discrimination due to free rides based on implicit knowledge and success know-how.

<Definition 2>If economic discrimination fails due to positive transaction costs and "free riding" caused by them in the implicit knowledge or know-how market, economic failure will occur.

This is a common phenomenon not only for the individual and corporation, but also for the national economy and civilization. The practice of free riding aiming at gaining success know-how or implicit knowledge without paying a due price impedes the development of top-ranking workers and enterprises. The reason is that if free riding in the implicit knowledge market becomes pervasive, its spread will lead to the dumbing-down of knowledge as bad money drives out good money.

In reality, the failure of the implicit knowledge market and the failure of economic development resulting from it are caused by imperfect information, which is the root cause of positive transaction costs. It is generally very difficult for humans, who are strangers to each other in this vast world, to know who performs what and how well the task is performed. The effort, money, and time that we must spend to identify these unknowns are called 'transaction costs' in economics terminology. Therefore, the market cannot avoid positive transaction costs, which can only weaken its ability to develop the economy. This problem becomes more serious in the implicit knowledge market, causing the society to face greater difficulties in emerging from a carriage manufacturing economy into a spacecraft manufacturing economy. Mainstream economists believe this is due to imperfect information. In fact, all problems arise from the fact that humans are not God and they know little about the world. This may be the reason why humankind in the past could not break away from an agricultural society or a carriage manufacturing economy for more than 10,000 years.

\subsection{The Correction of Market Failure: The Role of the Corporation and Government in Preventing Free Riding}

\section{(1) Joint-Stock Company System that Overcame Market Failure and Economic Failure}

Despite the lack of awareness about the world and the imperfection of information, humankind finally discovered a way to overcome the limitations inherent in human abilities. This is manifested in the organization of the corporation. It is a device that maximizes the motivation of employees to work by preventing free riding through economic discrimination based on their performance in the organization. Unlike the market, the "corporation" is a device in which people, previously unknown to each other, gather together to form an organization and face or interact with one another as a team.

development and different from unintentional behaviors such as a simple spreading process of the external effect discussed in mainstream economics, or the evolutionary reproduction process. The General Theory sees that economic development is a result of humans' intentional self-development efforts for their own success by actively responding to or changing the incentive system of the given surroundings. The theories of economic development must address the issue of how the institutional environment that regulates human behaviors should be changed into one that is development-friendly, for economic development is fundamentally a matter of human consciousness. 
This construct facilitates their mutual understanding of what task each person performs as well as their respective level of competency, thus enabling the reduction or elimination of transaction costs for economic discrimination. Thus, the corporation is more efficient than the market in identifying individual performance and providing rewards accordingly. Also, the more imperfect the information is, the more efficiently the corporation functions as a resource allocation system. Thus, an enterprise is an effective device that enables discriminatory rewards for each member's performance. In the end, the corporation is a device that expands the network of the market by fulfilling the function that the market cannot provide through economic discrimination. Furthermore, the corporation promotes the division of labor by extending the area of the so-called market economy.The corporation's function of transaction cost reduction and more efficient discrimination originate from its organizational characteristics, which are different from those of the market. A market transaction is a horizontal and democratic relationship based on agreements between the relevant parties. However, the decisions on the use of resources within the corporate organization are based on a hierarchical command system with the head of the organization at the top. Of course, firms can minimize transaction costs by replacing horizontal transaction relationships with a hierarchical command system. However, companies must also bear the additional costs for the management and operation of the organization. Thus, within the limits of positive organizational costs, the corporation can more efficiently perform the function of economic discrimination in the market ${ }^{13}$.

Historically, the corporate organization was a one-man business or a family enterprise which operated in the form of a smithy where goods such as carriages were produced before the Industrial Revolution. However, since the early 19th century, under the government's legal backing, the joint-stock company-type corporation was invented. As its capital size and the risk-bearing capacity increased infinitely, capitalist mass production finally started. The company law enacted in 1824 in the UK is known to be the predecessor of a modern joint-stock company system. In this process, the government actively promoted corporate activities in the name of industrial policies. In this way, the joint-stock company-type enterprise emerged as the economic subject responsible for organizing the production resources within the entire capitalist economy as well as the production activities, which contributed to the achievement of the Industrial Revolution.The General Theory of Economic Development particularly emphasizes the critical role that the corporation plays in the process of economic development. The development of the capitalist economy can take place only through the growth of the corporation. Therefore, it is reasonable to define the modern capitalist economy as a "corporate economy" 14 .

<Definition 3>The corporation is an effective device that enables discriminatory rewards depending on the individual's performance. Moreover, the development of the capitalist economy can take place only through the growth of the corporation. Therefore, it is reasonable to define the modern capitalist economy as "corporate economy".

\section{(2) The Role of Government in Economic Discrimination}

Nonetheless, the problem of free riding among companies still exists. As the subjects who are engaged in a market economy, corporations are also exposed to the free riding of their rivals on their own implicit knowledge or success know-how due to the market's failure in discrimination. The success know-how of the top successful companies is subject to the free riding of their rivals that were later established as public goods. This condition makes it impossible for the companies that were once successful to remain as the eternal winners in the market. As a result, the market structure does not allow for outstanding companies to receive the title of the most leading companies or to survive for an extended period of time. Therefore, just as bad money drives out good money, the spread of free riding among companies preclude the possibility of an economic advancement, as these outperforming companies disappear and only mediocre companies remain in the market.

Another economic subject to address this problem is the government, which is another public organization. Although the government also has the organizational characteristics of the corporation, what differentiates the former from the latter is that it is an ultimate exogenous coordinator of the national economy that sets rules within the market. If the corporation is a device that internalizes the implicit knowledge market that fails in discrimination due to free riding, the government is a device that internalizes the private economy that fails to advance economically due to transaction costs.

\footnotetext{
${ }^{13}$ Today, in the name of social democracy and economic democratization, there has been a movement to spread the so-called "democratization of management". This movement takes for granted the participation of the union in the management or requires the strengthening of the decision-making power of the union. This had led to a rising demand for a horizontal decision-making system for the distribution of resources within the organization of the corporation as well as for the transactions in the market. If the demand becomes excessive, it will have a negative impact on economic development by weakening the corporation's function of discrimination.

${ }^{14}$ Simon (1991) insists that it is more appropriate to define the capitalist economy as an "organization economy" rather than as a "market economy". This study, however, more specifically considers the structure as a "corporate economy".
} 
Through this function of internalization, companies can mobilize and cultivate excelling and talented individuals and resources through economic discrimination more efficiently than the market can. In turn, this movement can contribute to the development of the economy and the cultivation of outstanding workers and companies destined to be crowded out due to the free riding of the future rivals to follow. The government can perform the function of discrimination by supplying various public policies and economic systems. In addition, it can lead all economic subjects to the path of success by motivating them through economic discrimination.

<Proposition 1>In the case of the failure of the implicit knowledge or success know-how market in economic discrimination due to positive transaction costs and the free riding phenomenon, the corporation and government function as a device that compensates for the defect. Their role in economic discrimination enables an economic development.

\subsection{The Holy Trinity of Economic Development}

Due to the problem of free riding in the market, economic development fails as bad money drives out good money. Who, then, is responsible for preserving good money and how is it preserved to achieve economic development? Companies are able to retain outstanding talent, which can be considered good money crowded out by bad money due to free riding and achieve an economic advancement. However, since free riding arises from even among companies and drives out good money, it is difficult to see outperforming companies emerge and survive in the market. In this case, if the government can play the role of fostering these excellent enterprises, the economy can advance. Thus, while the market is involved in the achievement of explosive economic development by performing the function of discrimination inherent in it and the corporation corrects the market's failure in discrimination, the government corrects the failure in the preservation of good money (the birth of outstanding companies) in the corporate ecosystem. This system thereby enables a rapid economic development. The theory that explains this process is the "theory of the holy trinity of economic development"(See $<$ Figure 1>).

\section{Figure 1 Economic discrimination and the holy trinity of economic development}

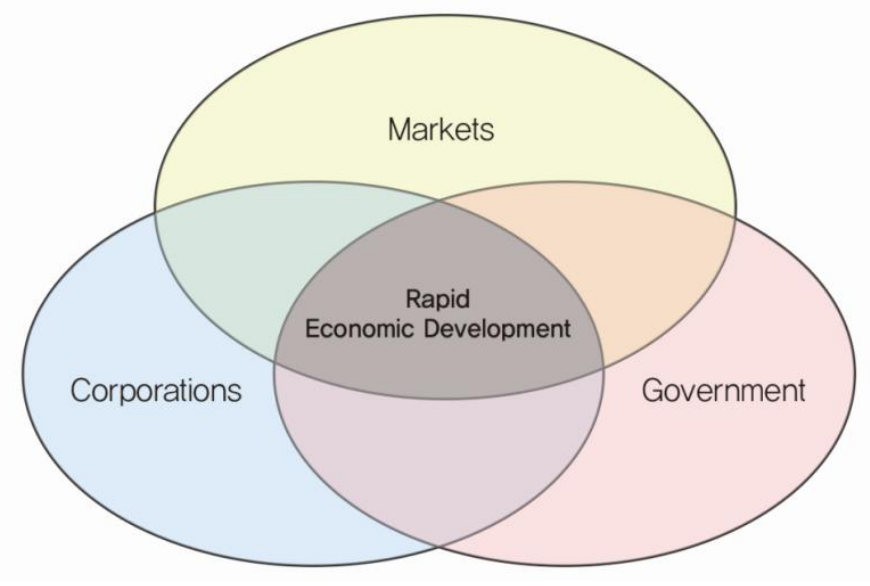

<Proposition 2>If the market, corporation, and the government successfully fulfill their respective role in economic discrimination as they function as an integrated body, the synergy leads to an economic development. This is the core of the "theory of the holy trinity of economic development".

From the perspective of the theory of the holy trinity of economic development, an economic development can only be made when the market, corporation, and government carry out the function of economic discrimination as an integrated body. The role of politics is also significant in this process. Politics can contribute to economic development only by ensuring that the market, corporation, and government can operate as one body in performing the function of economic discrimination. Thus, if politics falls into populism and produces egalitarian economic policies and systems, economic stagnation inevitably occurs.

\section{The Existing Criticism and Reevaluation of the Korean Heavy-Chemical Industrialization Policy}

This chapter examines the major criticisms of the Korean heavy-chemical industrialization policy and reevaluates it from the perspective of the General Theory of Economic Development.

First, we outline the critical viewpoints toward the heavy-chemical industrialization policy that have been raised in Korea to date. As noted above, most criticisms of the policy are based on the market-oriented thinking and logic, which ignores the role of the government as well as the merits of industrial policies. 
The following four major criticisms have been raised concerning the Korean heavy-chemical industrialization policy. First, the industrialization policy of the heavy-chemical industry was led by the government, and this led to the continuous practice of the government-controlled economy in Korea. Second, the heavy-chemical industrialization policy has caused the distortion of the allocation of resources in the financial and banking sectors. Third, excessive and redundant investment in the heavy-chemical industry has caused the waste of resources. Finally, the conglomerates fostered under the heavy-chemical industrialization policy have become a hotbed of monopoly and cozy relations between politics and business.

These positions first emerged during the Fifth Republic of Korea era in the early 1980s and have continued to maintain influence even to date ${ }^{15}$. Among those who have emphasized the positive effects of the heavy-chemical industrialization policy are Kim Jeong-ryeom (1995), Oh Won-cheol (1996, 2006), Kim Gwang-mo (2004), Kim Hyeong-a (2005), Park Yeong-gu (2008), and Park Gi-ju (2014). However, in the mainstream economic circles of Korea, critical viewpoints toward the policy are still dominant. In addition, only a few among the world economic circles support the industrial policy, which is unable to gain acceptance.

This phenomenon is mainly due to the market-oriented, mainstream resource allocation economic model, which is fundamentally skeptical of industrial policies. However, since no developmental economic model to replace this model exists, no convincing argument against the criticisms of the heavy-chemical industrialization policy has gained acceptance. Why is this so? First, in the absence of alternative economic development theories, both sides develop their debate based on the perfect competition equilibrium model, which is a market-oriented, main resource allocation economic model that inevitably accepts the role of the government in the exceptional case of market failure. Second, therefore, the proponents of pro-industrial policies are always forced to advance their opinions defensively, based on the theories on exceptional and special cases, rather than on general cases ${ }^{16}$.

However, this study intends to examine the myths and truths about the Korean heavy-chemical industrialization policy regarding its four major criticisms based on the General Theory of Economic Development, which perceives market failure as an ordinary phenomenon. New insights and implications can be gained if the existing issues concerning the Korea heavy-chemical industrialization policy including the role of the government are examined on the basis of this new economic developmental theory. From this point of view, this study examines the existing four major criticisms of the policy and develops new counterarguments against them. Based on this work, it is expected that an alternative, market-friendly industrial policy theory can be newly developed, which is discussed in another study by the researchers ${ }^{17}$.

\subsection{Myths and Truths Regarding the Criticism of the "Government-led Economy"}

The most important among the criticisms that the Korean heavy-chemical industrialization policy was problematic has revolved around the questions about "why the government intervenes in resource allocation" and "whether the government can excel the market in selecting winners through the intervention".

Government intervention or control, in the sense that the government intervenes in private economic activities, is not a concept that can be dichotomously assessed as either right or wrong. Rather, what matters is what type of government intervention it is. If government intervention or control aims at strengthening the function of the market, it will be beneficial or helpful to economic development. In the process of economic development, the government must play a wide variety of roles, and it is difficult to succeed in economic development without the active support from the government. It is generally perceived that government control impedes or is contrary to market function. However, the immediate question is "what is the function of the market?"

\footnotetext{
${ }^{15}$ In particular, after the declaration of the failure of the heavy-chemical industrialization policy at the beginning of the Fifth Republic of Korea, these critical positions on the policy began to be formed mainly by the Korea Development Institute, which is a national research institute of Korea. For details, see Korea Development Institute (1995), YooJeong-ho (2004), and the Compilation Committee for the 60-Year History of the Korean Economy (2010).

${ }^{16}$ As no alternative economic developmental model exists, in many cases, the debate representing both sides had to be based on the neoclassical mainstream economic model (i.e., resource allocation economic model). In this case, the probability that the proponents of pro-industrial policies will win is zero. The reason is that the neoclassical economic model, on which the debate is mainly grounded, is a perfect competition equilibrium model that, in essence, does not tolerate industrial policies. Thus, the debate inevitably reaches the conclusion that industrial policies are only useful in highly exceptional cases.

${ }^{17}$ Jwa, Sung-Hee\& Lee, Sung-Kyu (2018). "Myths and Truths about Korea's Industrialization Strategy: Searching for a New MarketFriendly Industrial Policy Theory”,Review of Institution and Economics, Vol. 12, No. 4, pp. 27-45.
} 
The question is posed because, without a correct understanding of market function, we cannot properly judge the merits and demerits of government intervention. Therefore, it is essential to understand the function of the market in order to know whether or not government control accords with market function.

Mainstream neoclassical economics perceives the market as a device to optimize resource allocation. This view presupposes that any external market intervention will hinder resource allocation, except in the case of an "obvious market failure". This viewpoint also considers that the allocation of resources by the market falls within the realm of God's will. However, such a point of view does not fully explain how the market achieves the optimization of resource allocation. In addition, the mainstream economics implicitly assumes that the market always produces the optimal allocation of resources. However, the market is imperfect in reality and does not always succeed in doing so. Therefore, it is difficult to know in advance whether government intervention will actually impede the optimal allocation of resources in the process. Thus, the mainstream economics, which regards the result of a comparative advantage in the market as optimal allocation, insists that government intervention against the allocation results in its distortion. Furthermore, even in the case that the result is insufficient for optimal allocation due to market failure, the model is reluctant to recognize the usefulness of other alternatives and remains unaware of the process and method through which the optimal allocation is reached.

On the other hand, according to the General Theory of Economic Development, the market is a device that ultimately increases the efficiency of resource allocation through economic discrimination. That is, the market is always conducting a market-led industrial policy that selects winners through economic discrimination. However, the market cannot fully perform this role due to the imperfection of information. In this case, the role of the government is required. In order for the government to contribute to economic development, it must reinforce its function of economic discrimination. That is, economic discrimination through government control or intervention can contribute to the success of industrial policies.

Furthermore, with respect to the selection of winners, as the market performs economic discrimination depending on market performance, the government should also practice economic discrimination based on market performance to complement the function of the market and to contribute to industrial development. This means that the government does not select the winners before their performance in the market is assessed (i.e., the pre-selection of winners). Instead, the winners are chosen depending on their market performance after their competition is finished, and are then provided support (i.e., the post-selection of winners). In this case, the government can effectively avoid the potential problem of the pre-selection of winners when choosing winners. Therefore, economic discrimination by the government based on market performance can contribute to the success of industry policies by effectively solving the challenge of the selection of winners (companies to be supported), thereby compensating for the weakness of the market in implementing industrial policies.

From this perspective, the criticism of the Korean heavy-chemical industry policy has been lacking in both practical and logical validity since economic discrimination by the government, which selects winners based on market performance after the competition, led to the development of the Korean heavy-chemical industry. Moreover, the viewpoint that economic discrimination by the market based on market performance is fair and that economic discrimination by the government based on the same market performance is unfair cannot be logically established.

\subsection{Myths and Truths Regarding the Criticism of the Distortion of Resource Allocation}

As discussed above, argumentation is weak for the assertion that Korea's policy of economic discrimination by the government based on market performance, which was adopted for heavy-chemical industrialization, brought out the distortion of resource allocation, more than the economic discrimination by the market. However, the market-oriented mainstream economics, which lacks awareness of the evidence of the assertion or is reluctant to accept it, still identifies the problem of resource allocation distortion in various aspects. This study examines the four criticisms raised so far regarding the distortion of resource allocation from the viewpoint of the General Theory of Economic Development.

First, the critics of the policy of economic discrimination by the government argue that the distortion of resource allocation would not have occurred in the case of the concentration of resources for fostering the export industry whereas the concentration of resources for nurturing the heavy-chemical industry resulted in the problem. This viewpoint is universal in the mainstream economic circles that consider Korea's growth model as an export-led growth model. However, this view exposes two problems. First, the criticism is based on the static comparative advantage theory. It assumes that in Korea, where labor is relatively abundant compared with capital, concentrating resources to foster the labor-intensive export industry in the agricultural society is desirable in terms of resource allocation. The theory also assumes, however, that the capital-intensive industry is not a good choice for the country. However, not only is this viewpoint contradictory but it is also, as pointed out earlier, inconsistent with the goals pursued by a rapid economic growth. 
Its essence lies in the mutual development of the capital-intensive industry and the labor-intensive industry. This means that economic complexity reaches a higher level through the mutual growth of the two industries. Therefore, the acceptance of the static comparative advantage theory is likened to the recommendation not to pursue economic development.

Second, the critics of the policy of economic discrimination by the government insist that the establishment of artificial barriers by the government in the process of supporting the heavy-chemical industry caused the distortion of resource allocation. That is, while the government did not confine the targets of the export industry promotion policy to specific industries, it allows only some selected industries to enter into the heavy-chemical industry sector (through the artificial barriers) and provides them with support. The critics of the policy believe this approach caused the distortion of resource allocation. Two counterarguments can be made against this viewpoint. First, this argument is logically contradictory as it considers the fostering of the capital-intensive heavy-chemical industry less desirable than the nurturing of the labor-intensive light industry, and, at the same time, it regards the export industry that reversediscriminates against non-tradable goods and agriculture as desirable. Next, we have previously mentioned that the term "industrial policy" is based on a misconception and should be called "discriminatory support policy for companies". Therefore, from the latter point of view, the key factor to the success of Korea's heavy-chemical industry was economic discrimination by the government, which chose competent companies based on their market performance, rather than selecting specific industries following the precedent of developed countries. From this perspective, we can understand more clearly that the success of the export industry was not a result of a noninterference policy for all companies in the export sector but a fruit of the policy of economic discrimination by the government that favored outperforming exporting enterprises based on their achievements in exporting. Thus, it is difficult to specify that the fostering of the heavy-chemical industry would have caused a more severe distortion of resource allocation than the cultivation of an export industry. It is practical to consider the argument for the reason, which is, that in both the cases, the dynamic efficiency of resource allocation was improved by the government's support for corporations that were excellent in exporting through economic discrimination. From this point of view, the interpretation that perceives the government's policy to foster export and heavy-chemical industries as "discriminatory" is not logically valid.

Third, the critics of the policy of economic discrimination by the government believe that the government caused "government-controlled finance" and the distortion of resource allocation by concentrating financial resources on the heavy-chemical industry. This viewpoint is also attributed to the lack of understanding of the market function. It also implies a negative viewpoint that regards government control as evil by nature. As mentioned earlier, what is important is what type of government intervention it is. The key to the debate regarding government-controlled finance is how to define the function of the bank as a major economic subject. The main function of the bank as an agent of financial resource allocation lies in its function of loan review. The function is associated with the function of discriminatory support based on the performance of individuals and corporations. Thus, it can also be regarded as the function of economic discrimination. It is apparent that economic development can occur only when this function is successfully performed. Banks in developed countries are successful in the fulfillment of the function. Those in underdeveloped countries, however, fail in properly performing the function due to the imperfection of information and the backwardness of the system. The function of loan review that leads to the differential financial support, depending on the performance of the corporation, is originally the task for banks to fulfill. However, as the banks in the past Korea were incapable of performing this task, the government took charge of providing differential financial support to companies based on the thorough evaluation of their performance in exporting. It is unreasonable to consider this arrangement as government-controlled finance and the distortion of resource allocation only because the function of loaning was performed by the government, rather than by private banks. The reason is that if government-controlled finance faithfully follows the principle of economic discrimination based on market performance as banks do, as in the case of Korea, it is difficult to conclude that government-controlled finance causes the distortion of resource allocation. However, it was the opportunity cost of the government-controlled finance policy that banks lost the opportunity to obtain the capacity in loan review function that they would have gained through much trial and error.

Fourth, the critics of the policy of economic discrimination by the government assert that the policy was not fair because it focused loans to some successful companies. In fact, this viewpoint has continued to serve as a major foundation for accusing the heavy-chemical industrialization policy of lacking "morality" to present times in terms of politics and economics. However, this viewpoint can also be regarded as a product of the lacking awareness of the function of economic discrimination, which is the essence of the market. The concentration of loans to successful companies is a natural result of the bank's fulfillment of its function of differential loan review. 
Therefore, it is not reasonable to state that the concentration of loans to some qualified companies caused the distortion of financial resources or that it was morally unjust following the condition that a differential loan system was fairly operated based on the market performance evaluation by the government that complemented the loan review function of the bank. Moreover, this principle can never be a defect to the fairness or morality of the policy. In this case, by agreeing with the viewpoint that the concentration of loans itself is a problem, one may deny the discrimination function of the capitalist market economy as well as the normal differential loan review function of financial institutions.

\subsection{Myths and Truths Regarding the Criticism of Excessive and Redundant Investment and the Oversupply of Facilities}

The excessive and redundant investment in the heavy-chemical industry has been always identified as a problem by the critics of the Korean heavy-chemical industrialization policy. However, the industry did not target domestic demand but rather the international market from the beginning. This approach is the reason why large-scale production facilities, aimed at realizing the economies of scale, were constructed. Therefore, the oversupply of facilities to the heavy-chemical industry sector was inevitable in the initial stage before export became active. However, the second oil shock that occurred in the late 1970s when large-scale production facilities were completed in Korea slowed down the international demand. As a further matter, the political turmoil caused by the assassination of President Park Chung-hee in 1979 led to negative growth in 1980. The aftermath of these incidents triggered the criticism of the oversupply of facilities that appeared to be a result of excessive and redundant investment. Nevertheless, the phenomenon was not only a partially intended outcome by the policy but also an unavoidable consequence of the unpredictable global economic change and the domestic political situation. However, the mainstream economic circles of Korea have regarded this circumstance merely as the "policy failure" of the government. This viewpoint can be attributed to the influence of those who held a negative viewpoint on the heavy-chemical industrialization policy. These groups included the existing domestic and foreign academia, some government officials, the World Bank, and the marketoriented neoclassical mainstream economists who began to work for the Fifth Republic of Korea government.

For example, YooJeong-ho (2004) asserted that the policy caused excessive investment to the heavy-chemical industry and the distortion of resource allocation between the light industry and heavy-chemical industries based on the data showing that the latter enjoyed lower effective marginal tax rates on corporate income and a higher capital intensity than the light industry, but was inferior by comparison in the marginal product of capital and exporting performance. However, such a result can be observed in the initial intensive investment stage of the heavy-chemical industry, which has a long gestation period. Thus, the outcome can be observed as normal and intended. It seems unreasonable to criticize the heavy-chemical industrialization policy for this reason. Most of the other criticisms are also exposing similar limitations. On the other hand, Park Yeong-gu (2008, Chapter 12) systematically refuted existing criticisms in terms of excessive investment on facilities, the marginal efficiency of capital, returns, and exports, for a longer period of time and in light of international experiences.

The challenges faced by the heavy-chemical industry from the late 1970s to the early 1980s were obstacles that Korea had to overcome for industrial advancement at the time. It is not appropriate to consider that these challenges were attributed to the failure of the industrial policy. The problem of excessive investment in the heavy-chemical industry is a very complicated issue that cannot be evaluated in the short term as is commonplace for other issues. This matter becomes likened to a battle in which only those who have endured hardships will ultimately win. Fortunately, however, Korea greatly advanced into an exporting powerhouse in the heavy-chemical industry sector in part due to the unexpected change in the world economic environment, which is the so-called "three-low boom" starting from 1985, though the country had accomplished restructuring in the early $1980 \mathrm{~s}^{18}$.

As it is difficult to claim that the difficulties faced by Korea in the heavy-chemical industry sector in the late 1970s were due to the failure of the industrial policy, it is also unfair to attribute the three-low boom to policy success. Rather, one can believe that heaven had sent hardships to Korea and rewarded it for its endurance with a new and good opportunity ${ }^{19}$. Therefore, the heavy-chemical industrialization policy is neither a failed policy nor an object of eradication, but what needed to ensue for the industrial revolution of Korea at the time. The heavy-chemical industrialization has become a valuable success experience of Korea.

\footnotetext{
${ }^{18}$ It was argued that there had been no actual restructuring, and that the attempt made to restructure had ratheraggravated the difficulties faced by the industry. See Park Yeong-gu (2008, Chapter 12).

${ }^{19}$ This belief is consistent with the idea connoted in the proverb "Heaven helps those who help themselves".
} 


\subsection{Myths and Truths Regarding the Criticism of the Creation of Conglomerate (Chaebol) System}

Some of the Korean mainstream economists criticize that heavy-chemical industrialization has created the conglomerate, or chaebol, system and that it is the cause of all the problems of the Korean economy today. They accuse the Park Chung-hee government's heavy-chemical industrialization policy of inciting all inequality thinking that no problems would have existed had the chaebol not come into being. In many cases, such a criticism is nothing more than an iteration of Karl Marx's critique of capitalism.

Surprisingly, most of the politicians, the majority of intellectuals, and even a considerable number of intellectuals in economics and business academics seem to agree with the viewpoint in Korea today.These companies, whether they are called "chaebol" or "conglomerates", were all started as small- and medium-sized enterprises (SMEs). In this regard, two theoretical and historical propositions must be clearly understood. First, Karl Marx insists that capitalist firms are the source of the capitalist exploitation of labor and economic inequality. However, according to the General Theory of Economic Development, capitalist economic development is the process of corporate growth itself. An industrial revolution is not achieved by SMEs. In developed countries, the growth process of SMEs into large corporations was a universal process of the industrial revolution and so was the case of Korea's economic development process. Korea achieved success not by fostering conglomerates but by effectively implementing policies to develop SMEs.As a result, these companies grew into large enterprises. Without the small companies that had once manufactured carriages in smithies and eventually transformed into large corporations that produce trains and automobiles, economic development in its true sense does not happen. The core of Korea's successful SME promotion policy was an economic discrimination strategy by government control behind its export industry promotion and heavy-chemical industrialization policies. The government raised the level of entrepreneurship in businesses by discriminatorily favoring and supporting the companies that helped themselves. It encouraged these corporations to engage in active competition in the global market with fierce determination by actively motivating them. The outcomes of the policies are economic development and the birth of large companies. This suggests that the emergence of conglomerates is the prerequisite for a rapid economic development. Leftist theorists may want to believe that the emergence of large corporations has no correlation with economic development, such that the dissolution of these large businesses would have no impact on the growth or development of the economy. However, as previously mentioned, economic theories and human history demonstrate that their belief is groundless.

Second, there are no convincing theoretical or empirical studies that support the assertion that the growth of large corporations have hampered Korea's economic development or increased the country's economic inequality. At best, only superficial statistical comparisons or normative and ideological arguments have been made to date. There is also no objective or scientific analysis that can serve as a foundation for their assertion ${ }^{20}$. The reason is that the mainstream economic circles of Korea still cannot provide a systematic theory of economic development that can identify the relationship between economic development and imbalance or inequality. Therefore, the "descendants" of Karl Marx ideologically insist that big business is the root of all evil. The General Theory of Economic Development presented in this study is of a new attempt to overcome this weakness in the rationale of mainstream economics.

Thus, the viewpoint that economic development would have occurred even without the success of the heavy-chemical industry or the growth of large corporations is merely an empty argument with no theoretical or historical basis. The adverse effects caused by the emergence of conglomerates, such as a monopoly and the cozy relations between politics and business, are undoubtedly problems that require resolution. However, it is not desirable to regard large corporations that have led economic development as the "beings that should not have been born" or to consider the fostering of the heavy-chemical industry as the "policy that should not have been implemented". This thought is no different from the claim of "romantic socialism" that humans need to return to the state where everyone is equally as impoverished as they were in the past agricultural society.

<Proposition 3>Korea's past heavy-chemical industrialization policy has been criticized for creating a governmentcontrolled economy, distortion of resource allocation, excessive and redundant investment, and the emergence of conglomerates. It is considered that these criticisms are not theoretically and historically valid. From the perspective of the "General Theory of Economic Development", Korea's heavy-chemical industrialization policy was a successful strategy.

\footnotetext{
${ }^{20}$ One of the leading proponents of this viewpoint is Jang Ha-sung (2017).
} 


\section{Conclusions}

Until today, the mainstream economics of Korea has sought the success equation of Korea's industrial development period in its export-led growth strategy. This viewpoint has led to various theoretical and policy distortions of the related facts. First, this viewpoint may be consistent with market-oriented thinking based on the comparative advantage theory. However, it lacks the logical understanding of how export-led policies ensure the transition from a carriage manufacturing economy into an automobile manufacturing economy in an agricultural society. That is, the theory is unable to rationalize how export-led growth leads to an economic development.

Also, the viewpoint shared by mainstream economists has also resulted in a major distortion of the success factors to the Korean economic development by neglecting the government's active policy efforts to achieve the advancement of the industrial structure through the implementation of related policies. In addition, the export-led growth hypothesis can result in the misleading of the public. That is, the public acceptance of this concept may lead it to believe that Korea was able to remarkably advance its industrial structure through exports to the world's trade markets and through the mysterious market forces. This would in contrast to the attribution of Korea's economic advancement through its own efforts. Lastly, some radical viewpoints even suggest that Korea would have achieved a higher economic growth rate than what was actually achieved-an annual average rate of about $9 \%$ from the 1960 s to the $1980 \mathrm{~s}$-without the government's "useless intervention" to foster the heavy-chemical industry. However, this study has drawn new implications for the significance of Korea's heavy-chemical industrialization policy by reevaluating it from the viewpoint of the General Theory of Economic Development.

By summarizing some of the key points and lessons presented so far, we conclude the discussionas follows. First, this study shows that although the export-led growth strategy or policy based on the principle of economic discrimination played an important role in the process of achieving an economic advancement in Korea, what ultimately contributed to the fulfillment of the country's industrial revolution was the success of the heavy-chemical industrialization strategy by transforming the Korean economy from one that was previously based on carriage manufacturing into one based on automobile manufacturing. In the end, the industrial revolution of the Korean economy would not have been achieved without the success of the heavy-chemical industrialization strategy. However, this study places greater emphasis on the fact that the policy respected the market's discrimination function and market performance and that these were the key factors to the success. At the same time, this study highlights the significance of the heavy-chemical industry promotion policy through economic discrimination by the government. In this regard, this type of policy can be defined as a "market-friendly industrial policy" ${ }^{21}$. This refers to an industrial policy that achieves economic growth through the mutual complementation of the functions of economic discrimination between the market and government policies.

Second, this study contends that Korea's economic development was one that was led by the growth of corporations and the paradigm of the corporate contribution to the national prosperity and development. This type of economic development provides a model in which the economy grows as companies grow. The reason is that the government's policy efforts to drive corporate growth through industrial policies were the driving force of Korea's economic development. The nation's past corporate upbringing policy concentrated large amounts of resources on outstanding companies and complemented the market's function of discrimination. This function greatly contributed to the explosive increase in the growth rate of enterprises and thus, the fostering of corporations with global competitiveness in the shortest period of time in the world's history. The major means of the corporate upbringing policy was the implementation of two policies. The first was the export promotion policy, which favored and supported only successful export companies. The second was the heavy-chemical industry promotion policy, which allowed only the companies with the highest level of export competitiveness to enter the industrial sector. That is, these policies favored corporations with excellent market performance by following the principles of justice such as the principle of award and penalty and the idea that heaven helps those who help themselves. This approach minimized the risk of free riding from occurring within the economy and society, thus motivating all corporations to the utmost extent. The government's economic discrimination strategy motivated Korean companies and people to voluntarily concentrate their efforts on competition for greater performance for about 20 years from the 1960s to the 1970s, eventually enabling them to experience the "Miracle on the Han River".

Third, this study intends to remind the latecomers seeking to follow the success model of Korea of the following facts. Although the industrial policy of economic discrimination by the government laid the foundation for the successful industrialization of Korea, it is worthy to emphasize that the policy was simply a necessary condition for economic development, rather than a sufficient condition. This is because the possibility of the success of an industrial and economic development policy can be raised only when it is accompanied by physical, social, and human infrastructures for a comprehensive national construction and economic development.

\footnotetext{
${ }^{21}$ Refer to Jwa and Lee (2018) for details. 
Specifically, institutional and physical infrastructures that are friendly to corporate growth must be built. The characteristics of such corporate growth-friendly infrastructures include a market and open economy system, the improvement of property rights system and the guarantee of economic freedom, the strengthening of general education and science and technology education, the fostering of the financial industry, and the supply of industrial complexes. Of course, these systems and policies can yield the intended results when they are introduced and implemented following the principle of economic discrimination, which is based on the principle of award and penalty.

Lastly, economic development is not a public good that anyone can achieve merely by expanding capital, supplying quality labor, and improving technology, as economics textbooks suggest. It would easier for a camel to pass through the eye of a needle than to achieve economic development. Without success know-how about how to expand capital, how to educate people and to develop them into skilled manpower, how to improve the level of science and technology, and how companies can effectively combine these factors to achieve success, the knowledge of economics is not helpful at all. The lesson from the Park Chung-hee government's industrial policy clearly demonstrates that the success know-how encompassing all of these factors lies in the thorough implementation of economicdiscrimination where the government helps only those who help themselves in accordance with the principle of award and penalty.

\section{References}

Acemoglu, Daron and James A. Robinson(2012), Why Nations Fail: The Origins of Power, Prosperity, and Poverty, New York: Crown Publishers.

Chandler, Alfred D. Jr. (1977), The Visible Hand: The Managerial Revolution in American Business, Cambridge, Mass. and London, England: The Belknap Press of Harvard University Press.

Chang, Ha-Joon (2002), Kicking Away the Ladder: Development Strategy in Historical Perspective, London: Anthem Press.

Devarajan, Shanta (2016), "Three reasons why industrial policy fails", Future Development, Brookings, Thursday, January 14, 2016.

Hayek, Friedrich von. (1984), "Competition As a Discovery Procedure", in The Essence of Hayek, edited by Nishiyama Chiaki and Kurt R. Leube. Stanford, California: Hoover Institution Press.

Jang, Ha-sung(2017), "The Korean Economy that the Nation Want: Coordinates and Goals",Paper presented at the annual meeting of Korea's Allied Economic Associations, Seoul, Korea.

Jwa, Sung-Hee (1994),The Operation of Korean Economy in the Globalized Era: Exploring a New Policy Paradigm, Sejong: Korea Development Institute.

Jwa, Sung-Hee(2006), A New Wealth of Nations, Seoul: Good Information Publisher.

Jwa, Sung-Hee(2008), Philosophical Foundation for Economic Development, Seoul: Seoul National University Press.

Jwa, Sung-Hee(2010), Success Economics of Korea, Seoul: Irwoldam.

Jwa, Sung-Hee (2014), “TheSucess Principle of SaemaeulUndong and Its Economic Implications”,SaemaeulUndong and Community Development Studies,Vol. 10, Gumi: Kyungwoon University Saemaeul Academy.

Jwa, Sung-Hee\& Lee, Sung-Kyu (2018),"Myths and Truths about Korea's Industrialization Strategy: Searching for a New Market-Friendly Industrial Policy Theory",Review of Institution and Economics, Vol. 12 (4).

Jwa, Sung-Hee\& Lee, Tae-Kyu (2006),The Structural Change and the Development of the Korean Movie Industry With a Focus on Vertical Integration, Seoul: The Korea Economic Research Institute.

Jwa, Sung-Hee(2017a), A General Theory of Economic Development: A Capitalist Manifesto, Edward Elgar: Cheltenham, UK.

Jwa, Sung-Hee(2017b), The Rise and Fall of Korea's Economic Development; Lessons for the Developing and Developed Economies, Cham, Switzerland: Palgrave-Macmillan.

Jwa, Sung-Hee(2018), “Understanding Korea's SaemaulUndong: Theory, Evidence, and Implication”, Seoul Journal of Economics, Vol. 31, No. 2, pp. 195-236.

Kim, Gwang-mo (2004),Park Chung-Hee's Devotion to the Heavy-Chemical Industry, Seoul: Gipa Rang.

Kim, Jeong-ryeom (1995). The 30-Year History of Korean Economy: Kim JeongRyeom's Memoirs, Seoul: JoongAngIlbo.

Kim, Hyeong-a(2005),A Double-Edged Sword, Seoul: Ilchokak.

Korea Development Institute (1995), The Korean Economy from 1945 to 1995: Performance and Vision for the 21st Century.

Oh, Won-Cheol (1996),The Construction of a Korean-Style Economy, Seoul:KIA Economic Research Institute.

Oh, Won-Cheol (2006),A Dauntless Spirit and the Miracle on the Han River: How Park Chung-heeMade an Economic Powerhouse, Seoul: Dong Suh Book. 
Park, Gi-Ju et al. (2014). The Heavy-Chemical Industrialization of Korea and Changes in the Society, The National Museum of Korean Contemporary History Collection, Volume 3, Seoul: The National Museum of Korean Contemporary History.

Park, Yeong-gu (2008),An Introduction to the Study on the Korean Heavy-Chemical Industrialization, Seoul: Haenam Publishing Co.

Rodrik, Dani(2008), "Normalizing Industrial Policy", a paper prepared for the Commission on Growth and Development, accessed 1 June 2016 at http://j.mp/1RO8XcY.

Sakong, Il and YoungsuKoh (ed.)(2010), The Korean Economy: Six Decades of Growth and Development, The Committee for the 60-years History of Korean Economy, Seoul: Korea Development Institute.

Simon, Herbert A. (1989), “Organization and Market”, Journal of Economic Perspectives, Vol. 5(2), pp. 25-44.

Thaler, Richard H. \&Sunstein, Cass R. (2009), Nudge: Improving Decisions about Health, Wealth, and Happiness (JinHwan Ahn, Trans.), Seoul: Readers Book (Original work published 2008).

The Committee for the 60-Year History of Korean Economy (2010), The 60-Year History of Korean Economy, Sejong: Korea Development Institute.

Yoo, Jeong-ho (2004),The Key to Survival: The Eradication of Government Control and the Pursuit of Market Economy, Chaeksesang Collection Our Times, Volume 89. Seoul: Chaeksesang. 